\title{
A magnetically-separable $\mathrm{H}_{3} \mathrm{PW}_{12} \mathrm{O}_{40} @ \mathrm{Fe}_{3} \mathrm{O}_{4} / \mathrm{EN}-\mathrm{MIL}-101$ catalyst for the one-pot solventless synthesis of $2 \mathrm{H}$-indazolo[2,1-b] phthalazine-triones
}

\author{
Alireza Hashemzadeh ${ }^{a}$, Mostafa M. Amini ${ }^{a}$, Reza Tayebee ${ }^{b, c^{*}}$, Atefeh Sadeghian $^{c}$, Lee J. Durndell, \\ Mark A. Isaacs, ${ }^{d}$ Amin Osiashtiani ${ }^{d}$, Christopher M. A. Parlett ${ }^{d}$, Adam F. Lee ${ }^{d *}$ \\ ${ }^{a}$ Department of Chemistry, Shahid Beheshti University, G.C., Tehran 1983963113, Iran \\ ${ }^{b}$ Department of Chemistry, School of Sciences, Hakim Sabzevari University, Sabzevar 96179-76487, \\ Iran \\ ${ }^{c}$ Department of Chemistry, Payam Noor University, Tehran 19395-4697, Iran \\ ${ }^{d}$ European Bioenergy Research Institute, Aston University, Birmingham B4 7ET, UK \\ *Corresponding authors: Rtayebee@hsu.ac.ir (+98-51-44410310); a.f.lee@aston.ac.uk.
}

\begin{abstract}
A magnetic inorganic-organic catalyst, PTA@ $\mathrm{Fe}_{3} \mathrm{O}_{4} / \mathrm{EN}-\mathrm{MIL}-101$ (EN=ethylenediamine, PTA=phosphotungstic acid) was fabricated and characterized by XRD, HRTEM, FESEM, UVVis, TGA-DTA, FT-IR, XPS and porosimetry. PTA retained the parent Keggin structure upon dispersion throughout the amine-functionalized chromium terephthalate metal-organic framework, over which magnetic $\mathrm{Fe}_{3} \mathrm{O}_{4}$ nanoparticles were previously introduced. The resulting composite heterogeneous solid acid was an active catalyst for the one-pot synthesis of diverse $2 \mathrm{H}$-indazolo[2,1-b] phthalazine-triones in good $\rightarrow$ excellent yields under mild, solventless condition, and offers facile separation and excellent recyclability.
\end{abstract}

Keywords: metal-organic framework; magnetic nanoparticles; heteropolyacid; phthalazinetrione

\section{Introduction}

The design, synthesis and application of active and selective heterogeneous catalysts inspired by molecular analogues has been the focus of intensive recent research, resulting in the fabrication of diverse nanocomposites and nanoporous frameworks [1-4]. Critical design parameters for nanocomposite catalysts include ease of fabrication, separation and recycle and on-stream stability, which together influence their suitability for the large-scale commercial production of bulk and speciality chemicals and pharmaceuticals [5-7]. Of the many naturally occurring and synthetic catalytic materials available, metal-organic frameworks (MOFs) have risen in prominence for applications in organic synthesis due to their tunable microporosity 
(and more recently micro/mesoporosity [8]), extremely high surface areas, and wide range of pre- and post-synthetic routes to incorporate different chemical functionality [9-11].

Some MOFs offer vacant metal atom coordination sites which can be activated thermally, under vacuum, or through solvent exchange to enable their post-functionalization. Such coordinatively unsaturated MOFs are potential Lewis acid catalysts, and can act as structural building blocks in synergy with co-catalysts to generate multifunctional catalysts [12-15]. The attachment of magnetic nanoparticles to inorganic and organic backbones and fabrication of magnetic metal-organic frameworks (MMOFs) [16] unlocks opportunities to create novel multifunctional catalysts [17] amenable to facile separation and recycling.

The evolution of benign catalytic routes to the synthesis of structurally diverse active compounds for new therapeutic uses remains challenging [18-21]. Recently, phthalazine heterocyclic derivatives have attracted attention due to their high therapeutic value in analgesic, anti-inflammatory, antimicrobial, antithrombotic, antidepressant, diuretics, antihypertensive, antitubercular, and anti-HIV treatments [22]. Flexible synthetic routes to new scaffolds for generating various drug-based phthalazines thus represent a high of priority for catalyst design [22-24]. In this context, previous research has focused on catalytic functions immobilized on nanoparticles [25-30], wherein the catalytic surface area is related to the particle size and shape, and is generally too low to provide high activity. Nanoparticle catalysts may also require costly separation methods such as ultracentrifugation, although the application of magnetic $\mathrm{Fe}_{3} \mathrm{O}_{4}$ nanoparticles as a template can circumvent this issue [31-33]. Briefly, new composites made by immobilizing $\mathrm{Fe}_{3} \mathrm{O}_{4}$ nanoparticles onto functional MOFs could help in meeting the preceding goals, a high area catalyst offering facile, magnetic separation.

Here, we extend our recent efforts to develop efficient catalysts prepared from simple, low cost materials for atom economical and energy efficient organic synthesis [34-39], through the design of a MMOF incorporating $\mathrm{H}_{3} \mathrm{PW}_{12} \mathrm{O}_{40}$ (phosphotungstic acid, PTA) guest molecules to introduce the Brönsted acidity required for one-pot $2 \mathrm{H}$-indazolo[2,1-b]phthalazine-triones synthesis [40-43]. Chromium(III) terephthalate MOF, MIL-101(Cr) is a promising framework upon which to fabricate such catalysts, since it possesses a high surface area, good thermal and chemical stability, large mesopore channels $(\sim 2.9$ and $3.4 \mathrm{~nm})$ and wide pentagonal and hexagonal microporous windows (1.2 and $1.6 \mathrm{~nm}$ respectively) which facilitate rapid in-pore transport of substrate and products [15]. In MIL-101(Cr), Lewis acidic chromium vertices enable the coordination of ethylenediamine (EN) via simple post-modification. The large pore windows and channels facilitate subsequent in-pore anchoring of PTA to the amine moieties within EN-MIL-101(Cr) and hence Brønsted acidity, and the introduction of $\mathrm{Fe}_{3} \mathrm{O}_{4}$ 
nanoparticles which confer strong ferromagnetism and hence aid catalyst separation and reuse. This approach affords a magnetically separable, inorganic-organic hybrid catalyst for the one-pot condensation of phthalhydrazide, aromatic aldehydes, and dimedone to $2 \mathrm{H}$ indazolo[2,1-b] phthalazine-trione derivatives (Scheme S1).

\section{Experimental section}

\subsection{Materials and methods}

All chemicals were obtained from commercial sources (Aldrich and Merck) and used without further purification. Scanning electron microscope (SEM) micrographs were taken using a KYKY-EM3200 microscope (acceleration voltage $26 \mathrm{kV}$ ). HRTEM measurements were performed on a Philips TECNAI-20T electronic microscope operated at 200 $\mathrm{kV}$. Fourier transform infrared (FT-IR) spectra were recorded on a Bomem MB-Series FT-IR spectrometer. Ultraviolet-visible (UV-Vis) spectra were obtained on a Shimadzu Model UV2550 spectrophotometer. Melting points were recorded on a Barnstead electrothermal type 9200 melting point apparatus. ${ }^{1} \mathrm{H}$ - and ${ }^{13} \mathrm{C}-\mathrm{NMR}$ spectra were recorded on a Bruker AVANCE $300 \mathrm{MHz}$ spectrometer. Typical ${ }^{1} \mathrm{H}$ NMR parameters were 10 scans averaged, $2 \mathrm{~s}$ delay time, $14.6 \mu$ s pulse length; and for ${ }^{13} \mathrm{C}$ NMR 1024 scans averaged; 2 s delay time, and $130 \mu$ s pulse length, using TMS as an internal reference. Thermal analysis (TGA-DTA) was carried out using a Bahr STA-503 instrument at a heating rate of $10{ }^{\circ} \mathrm{C} \min ^{-1}$ in air. Powder X-ray diffraction (XRD) patterns were obtained on a STOE diffractometer using $\mathrm{Cu} \mathrm{K}_{\alpha}$ radiation $(\lambda=$ $0.15418 \mathrm{~nm}$ ). XPS analysis was performed on a Kratos Axis HSi photoelectron spectrometer equipped with a charge neutralizer and magnetic focusing lenses, employing monochromatic $\mathrm{Al} \mathrm{K}_{\alpha}$ radiation $(1486.6 \mathrm{eV}$ ) with energy referencing to the $\mathrm{C} 1 \mathrm{~s}$ peak at $284.8 \mathrm{eV}$. Porosimetry measurements were conducted by $\mathrm{N}_{2}$ physisorption on a Quantachrome Nova 4200e porosimeter with data analysis employing Novawin v11.0 software. Samples were degassed at $120{ }^{\circ} \mathrm{C}$ for $4 \mathrm{~h}$ prior to analysis by nitrogen adsorption at $-196{ }^{\circ} \mathrm{C}$, with BET surface areas calculated over the range $\mathrm{P} / \mathrm{P}_{0}=0.05-0.35$ where a linear relationship was maintained, while pore size distributions were calculated using the BJH model from the desorption isotherm. A freeze dryer (Model FD-10, Pishtaz Equipment Engineering Co, Iran) was utilized for occasional drying of samples if needed. Elemental analysis was performed with a Varian VistaPRO ICP-OES and Thermo Scientific Flash 2000 organic elemental analyzer. Synthesis of MIL-101(Cr) was confirmed by comparison of its spectral and physical data with those of 
previously reported [44]. All prepared indazolophthalazine-triones were known compounds and their spectral data was compared with the literature to confirm successful synthesis [36].

\subsection{Preparation of chromium(III) terephthalate metal organic framework [MIL- $101(\mathrm{Cr})]$}

MIL-101(Cr) was synthesized and purified according to the reported literature [45]. Briefly, 40 $\mathrm{mL}$ of deionized water was added to a mixture of ground, powdered terephthalic acid (1.66 g, $10 \mathrm{mmol})$ and $\mathrm{Cr}\left(\mathrm{NO}_{3}\right)_{3} .9 \mathrm{H}_{2} \mathrm{O}(4.0 \mathrm{~g}, 10 \mathrm{mmol})$. The mixture was sonicated resulting in a darkblue suspension, which was then poured into a $100 \mathrm{~mL}$ Teflon-lined stainless steel autoclave; the autoclave was then sealed and heated to $220{ }^{\circ} \mathrm{C}$ (heating rate $1 \% \mathrm{~min}$ ) for $24 \mathrm{~h}$. After hydrothermal processing, the autoclave was slowly cooled to ambient temperature, and the green suspension of MIL-101(Cr) thus obtained then separated by centrifugation (at $9000 \mathrm{rpm}$ for 10 minutes). The crude product was rinsed with water, methanol, and acetone, then centrifuged and purified by $10 \mathrm{~min}$ ultrasonication with $25 \mathrm{~mL} \mathrm{~N}, \mathrm{~N}$-dimethylformamide after which it was kept at $70{ }^{\circ} \mathrm{C}$ overnight. The final pure solid was obtained following additional centrifugation and repeated washing with methanol and acetone, and further overnight drying at $75{ }^{\circ} \mathrm{C}$. The final isolated yield was $42 \%$. MIL-101(Cr) was characterized by powder XRD and compared with the simulated single-crystal pattern from Mercury 3.8 software (Fig. 1) [44]. ICP-OES analysis gave the bulk Cr loading as $21 \mathrm{wt} \%$.

\subsection{Synthesis of EN-MIL-101}

MIL-101 grafted with ethylenediamine (EN) was synthesized according to a previously reported procedure [46]. $1.0 \mathrm{~g}$ of MIL-101 was activated at $150{ }^{\circ} \mathrm{C}$ for $24 \mathrm{~h}$ and then added to anhydrous toluene $(60 \mathrm{~mL})$ and ethylenediamine $(0.09 \mathrm{~g}, 1.4 \mathrm{mmol})$. The mixture was stirred under reflux for $12 \mathrm{~h}$ and then centrifuged and washed repeatedly with deionized water/ethanol $(1: 1)$ and finally dried at room temperature for $24 \mathrm{~h}$. The bulk $\mathrm{N}$ loading by elemental analysis was $8.1 \mathrm{wt} \%$.

\subsection{Synthesis of $\mathrm{Fe}_{3} \mathrm{O}_{4} / \mathrm{EN}-\mathrm{MIL}-101$}

$\mathrm{Fe}_{3} \mathrm{O}_{4} / \mathrm{EN}-\mathrm{MIL}-101$ was prepared adapting a literature synthesis of $\mathrm{Fe}_{3} \mathrm{O}_{4} / \mathrm{MIL}-101$ [47]. 0.40 $\mathrm{g}(2 \mathrm{mmol})$ of $\mathrm{FeCl}_{2} .4 \mathrm{H}_{2} \mathrm{O}$ and $0.65 \mathrm{~g}(4 \mathrm{mmol}) \mathrm{FeCl}_{3}$ were added to an aqueous suspension $(200 \mathrm{~mL})$ of $1.0 \mathrm{~g}$ EN-MIL-101. The mixture was briefly sonicated and then vigorously stirred and degassed with nitrogen for $1 \mathrm{~h}$. Aqueous $\mathrm{NH}_{4} \mathrm{OH}(15 \mathrm{~mL}, 25 \%)$ was then added resulting in a black suspension which was magnetically separated and washed with copious deionized 
water until the washing were $\mathrm{pH}$ 7. The final nanocomposite was dried at room temperature in air and designated $\mathrm{Fe}_{3} \mathrm{O}_{4} / \mathrm{EN}-\mathrm{MIL}-101$. The bulk Fe loading by ICP-OES was $37 \mathrm{wt} \%$.

\subsection{Synthesis of PTA@ @ Fe3O4/EN-MIL-101}

$1.0 \mathrm{~g} \mathrm{Fe}_{3} \mathrm{O}_{4} / \mathrm{EN}-\mathrm{MIL}-101$ was suspended in a methanolic solution of phosphotungstic acid (1.0 $\mathrm{g}$ in $50 \mathrm{~mL}$ ), and the mixture briefly sonicated and then stirred at ambient temperature for $6 \mathrm{~h}$. The resulting solid was separated and repeatedly washed with methanol and water, then dried under reduced pressure and designated PTA@ $@ \mathrm{Fe}_{3} \mathrm{O}_{4} / \mathrm{EN}-\mathrm{MIL}-101$. The bulk W loading from ICP-OES was $12.9 \mathrm{wt} \%$ (equivalent to $16.9 \mathrm{wt} \%$ PTA), with loadings of other elements as follows: Cr 9.7 wt $\%$ and Fe 29.1 wt $\%$. The overall synthesis is summarized in Scheme 1.
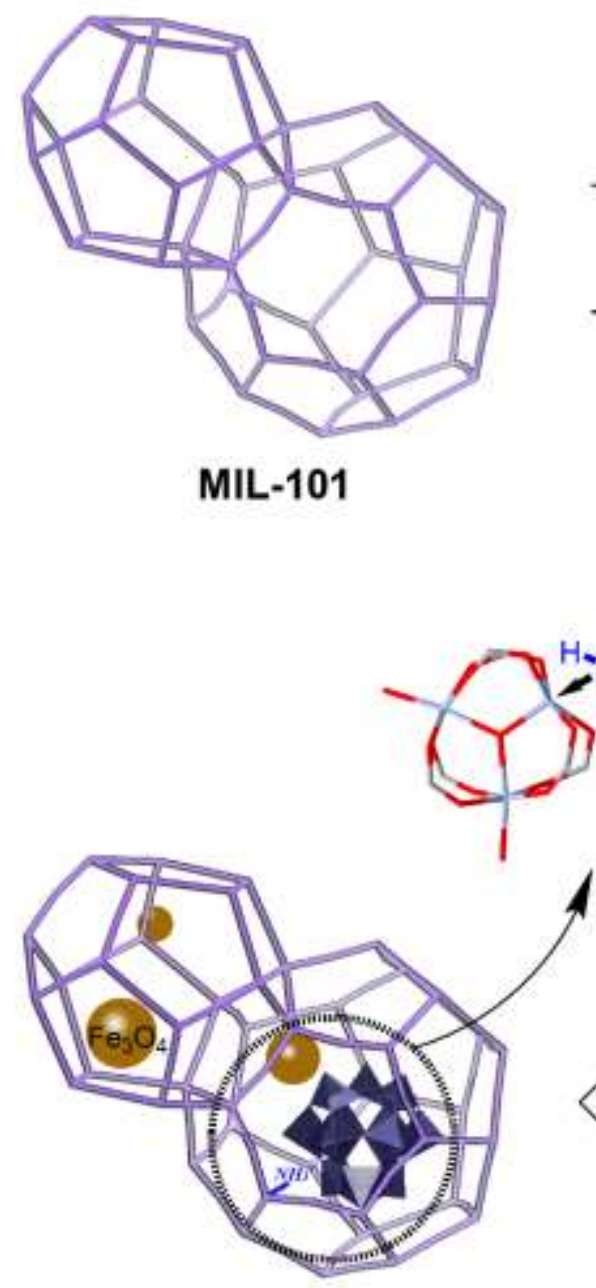

PTA@Fe ${ }_{3} \mathrm{O}_{4} / \mathrm{EN}-\mathrm{MIL}-101$
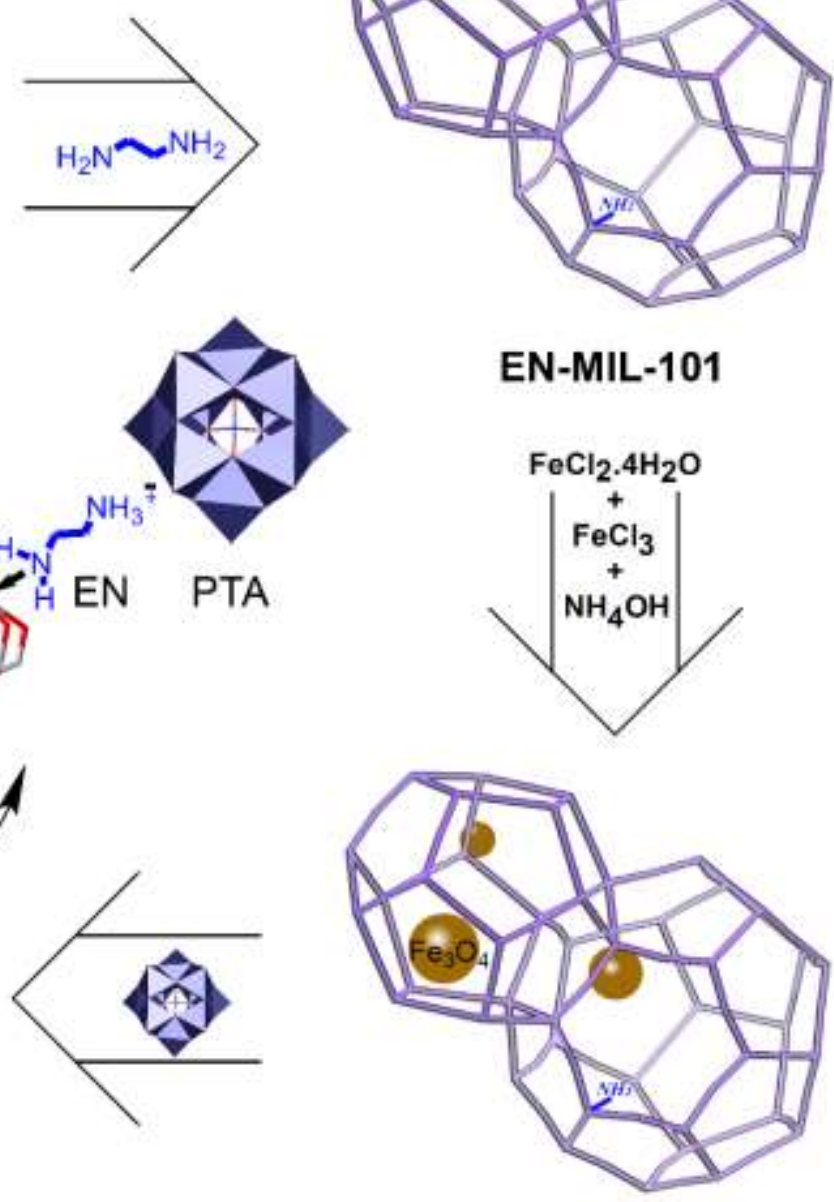

$\mathrm{Fe}_{3} \mathrm{O}_{4} / \mathrm{EN}-\mathrm{MIL}-101$

Scheme 1. Synthetic route to PTA@ $\mathrm{Fe}_{3} \mathrm{O}_{4} / \mathrm{EN}-\mathrm{MIL}-101$. 


\subsection{General procedure for the preparation of $2 \mathrm{H}$-indazolo-[2,1-b]phthalazine- 1,6,11(13H)-triones}

To a mixture of aldehyde $(0.25 \mathrm{mmol})$, phthalhydrazide $(0.25 \mathrm{mmol})$ and dimedone $(0.25$ mmol), PTA@ $\mathrm{Fe}_{3} \mathrm{O}_{4} / \mathrm{EN}-\mathrm{MIL}-101$ (0.02 g) was added and the mixture warmed to $100{ }^{\circ} \mathrm{C}$ to initiate reaction whose progress was followed by TLC. After reaction, hot ethanol $(5 \mathrm{ml})$ was added to the reaction mixture and stirred for $5 \mathrm{~min}$. The heterogeneous solid catalyst was then quickly filtered off, and the filtrate cooled to $5{ }^{\circ} \mathrm{C}$ to precipitate the desired product. The resulting solid product was further purified by recrystallization in aqueous ethanol $(25 \%)$. Pure products were identified by comparison of their physical data with those of known 2H-indazolo[2,1-b]phthalazine-1,6,11-(13H)-triones.

\section{Results and discussion}

\subsection{Structural characterization}

X-ray diffraction patterns of MIL-101, EN-MIL-101, $\mathrm{Fe}_{3} \mathrm{O}_{4} / \mathrm{EN}-\mathrm{MIL}-101$ and PTA@ $\mathrm{Fe}_{3} \mathrm{O}_{4} / \mathrm{EN}-\mathrm{MIL}-101$ are shown in Fig. 1. In all cases the diffractograms were consistent with the simulated single crystal pattern for MIL-101, evidencing retention of the parent MOF framework throughout the synthesis. However, the peak width and intensities of (notably low angle) reflections for the synthetic MOFs increased and decreased respectively following each synthetic step, indicating a progressive decrease in crystallinity. Although nearly all simulated (hkl) reflections of MIL-101(Cr) were conserved in the experimental powder XRD pattern of the final PTA@ $\mathrm{Fe}_{3} \mathrm{O}_{4} / \mathrm{EN}-\mathrm{MIL}-101$, no reflections characteristic of the free phosphotungstic acid were observed in the PTA@ $@ \mathrm{Fe}_{3} \mathrm{O}_{4} / \mathrm{EN}-\mathrm{MIL}-101$ sample, indicative of a high dispersion, since PTA reflections would only be observed from an extended crystalline network of Keggins. The absence of PTA reflections for silica supported analogues has likewise previously been attributed to highly dispersed (isolated or a 2D monolayer) Keggins [48, 49], even for loadings approaching $26 \mathrm{wt} \%$ (versus $\sim 17 \mathrm{wt} \%$ PTA in this work). Characteristic reflections of magnetite $\left(\mathrm{Fe}_{3} \mathrm{O}_{4}\right)$ were observed for $\mathrm{Fe}_{3} \mathrm{O}_{4} / \mathrm{EN}-\mathrm{MIL}-101$ and PTA $@ \mathrm{Fe}_{3} \mathrm{O}_{4} / \mathrm{EN}-\mathrm{MIL}-101$ (Fig. 1). Note that the overall crystallinity decreased following PTA incorporation into the magnetic composite, presumably due to structural distortions arising from accommodating the bulky anion within the small mesopores and/or microporous windows. Note that MIL-101(Cr) possesses $1.6 \mathrm{~nm}$ hexagonal windows [50] and hence is certainly able to accommodate individual Keggin units of PTA (diameter $\sim 1.2 \mathrm{~nm}$ ), and that $\mathrm{Fe}_{3} \mathrm{O}_{4}$ nanoparticles have also previously been accommodated in MIL-101(Cr) following the same synthetic route adopted in our work [47]. 


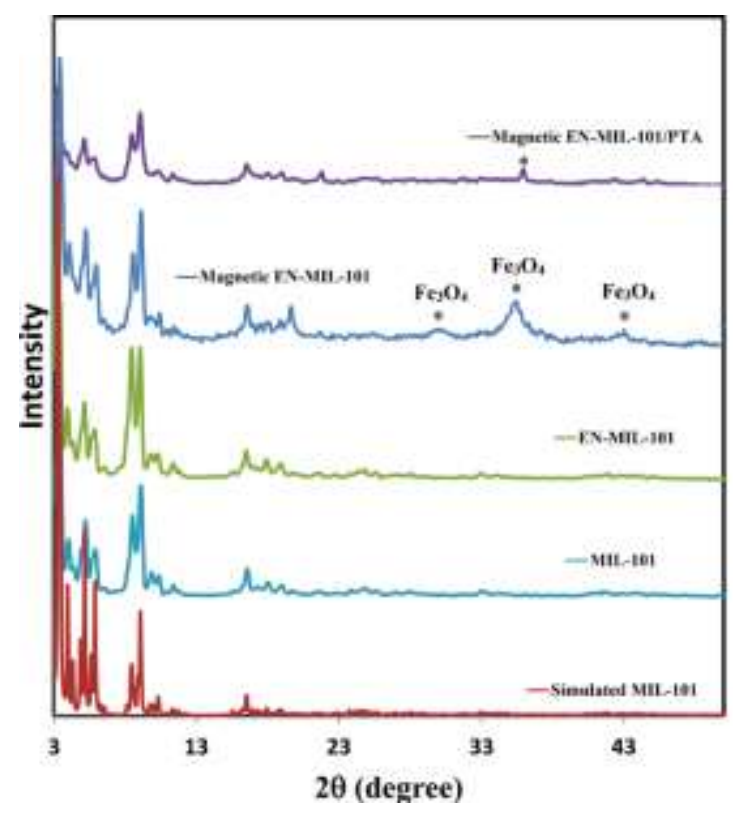

Fig. 1. X-ray diffraction patterns of parent and functionalized MOFs.

Nitrogen porosimetry of the parent and functionalized MOFs revealed a significant decrease in the surface area from around $2000 \mathrm{~m}^{2} \cdot \mathrm{g}^{-1}$ for MIL-101 to $<150 \mathrm{~m}^{2} \cdot \mathrm{g}^{-1}$ (accompanied by a similar magnitude decrease in the pore volume), even following the first ethylenediamine functionalization step, evidencing significant pore blockage (Fig. 2) and hence in-pore incorporation of the various functionalities consistent with the structural distortion of the parent MIL-101(Cr) observed by XRD.

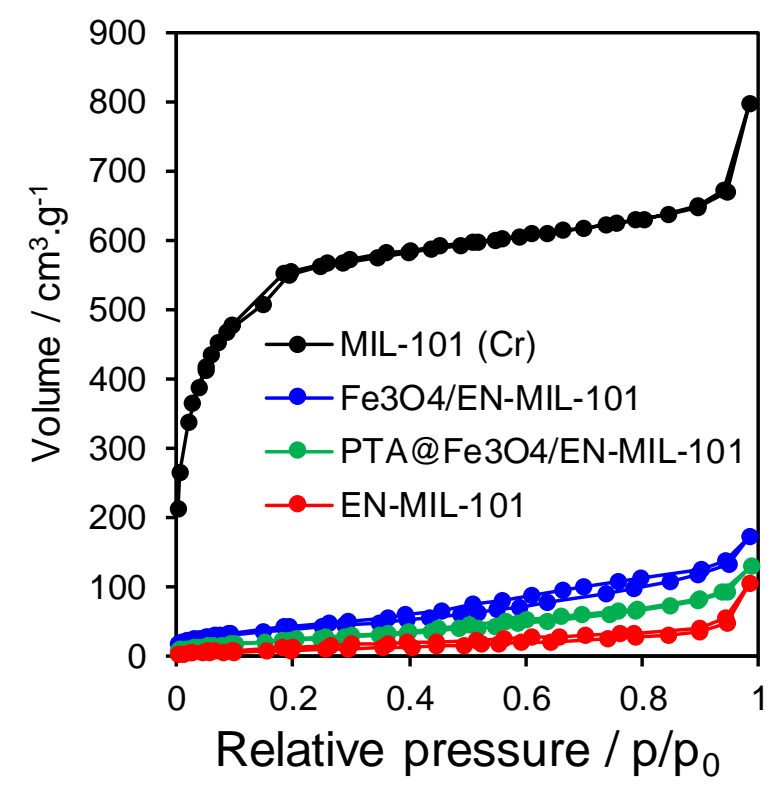

Fig. 2. $\mathrm{N}_{2}$ adsorption-desorption isotherms for parent and functionalized MOFs. 
As expected, FESEM images of MIL-101 (Fig. 3a) exhibited well-defined double pyramidal crystallites; however, post-modification the final material (Fig. 3b-c) revealed micron-scale aggregates of semi-spherical particles of approximately $25 \mathrm{~nm}$ diameter. Bulk elemental mapping by energy dispersive $\mathrm{X}$-ray (EDX) analysis revealed a uniform distribution of tungsten (Fig. S1).
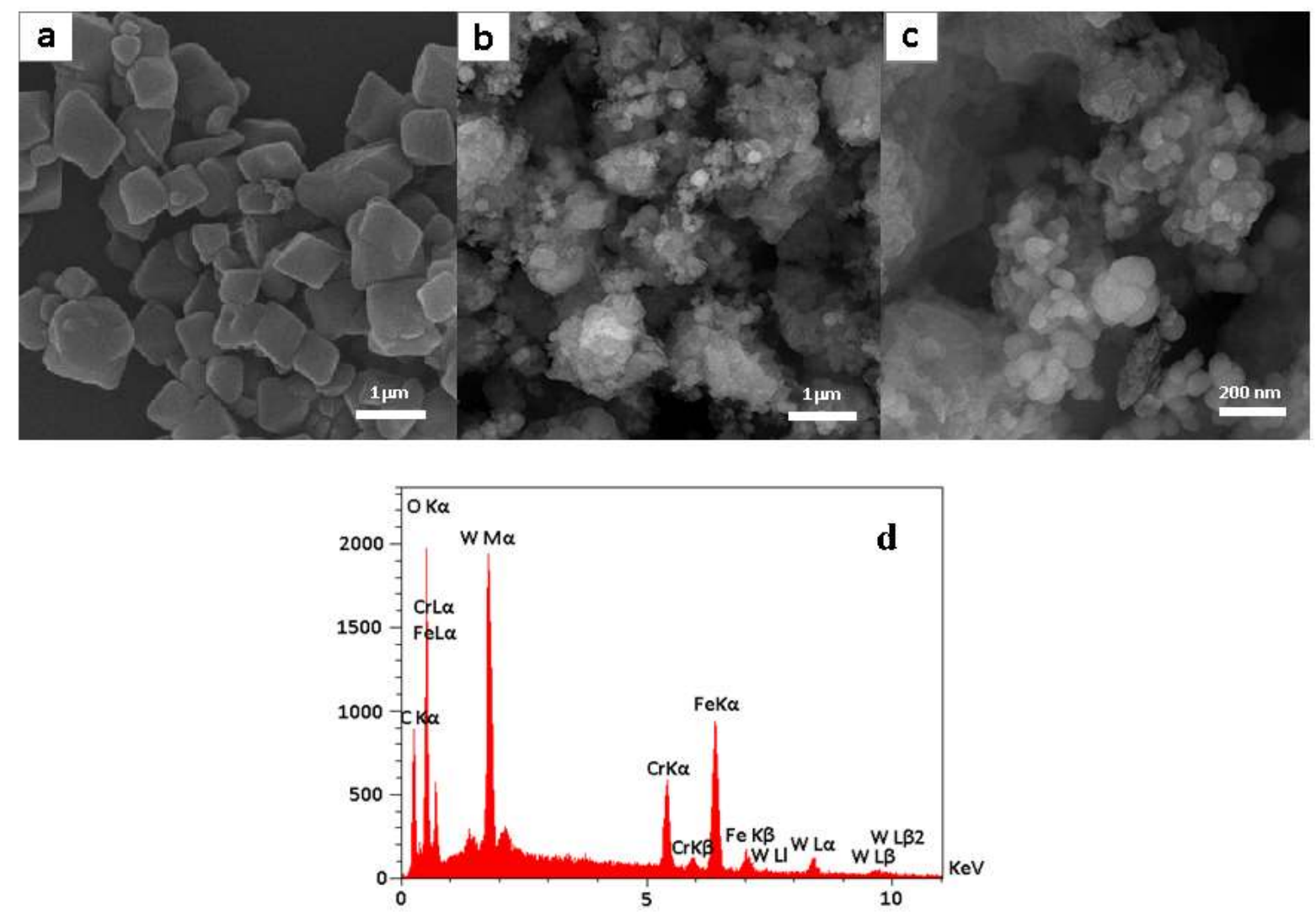

Fig. 3. FESEM images of MIL-101 (a), PTA@ $@ \mathrm{Fe}_{3} \mathrm{O}_{4} / \mathrm{EN}-\mathrm{MIL}-101$ in low and high magnification (b and c), and EDX analyses of PTA@ $@ \mathrm{Fe}_{3} \mathrm{O}_{4} / \mathrm{EN}-\mathrm{MIL}-101$ (d).

TEM of the parent and functionalized MOFs highlighted the ordered mesopore channels within the MIL-101 crystallites and their preservation following amine functionalization (Fig. 4). Bright and dark-field TEM of the iron oxide functionalized EN-MIL101 sample revealed the presence of high contrast nanoparticles with a relatively broad size distribution between $5-50 \mathrm{~nm}$, and lattice fringes of $0.25 \mathrm{~nm}$ consistent with $\mathrm{Fe}_{3} \mathrm{O}_{4}$ (Fig. S2) [51]. Subsequent heteropolyacid addition resulted in a uniform distribution of high contrast features throughout the $\mathrm{Fe}_{3} \mathrm{O}_{4} / \mathrm{EN}-\mathrm{MIL}-101$ sample. 


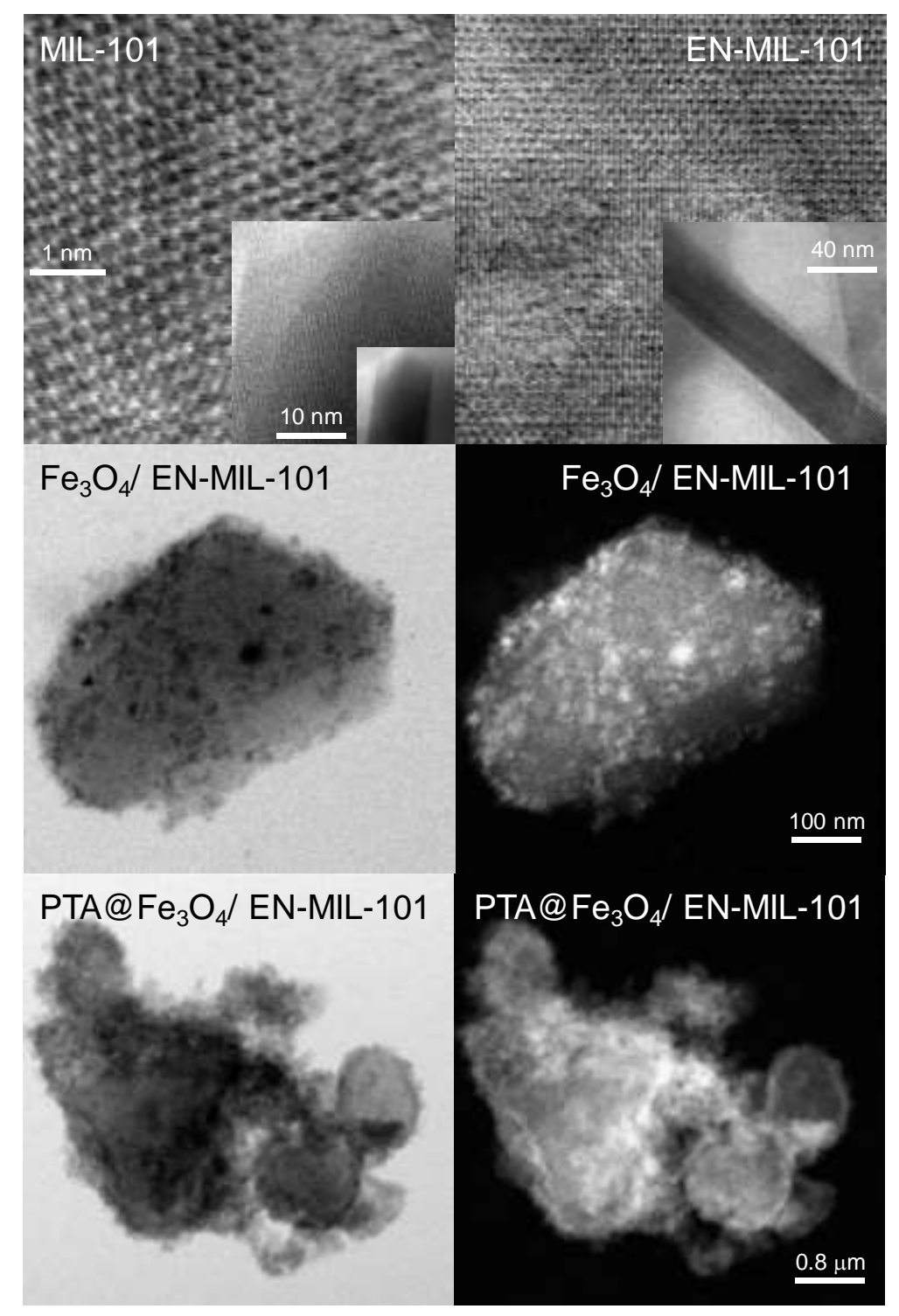

Fig. 4. Dark and bright-field TEM images parent and functionalized MOFs.

The UV-Vis spectrum of phosphotungstic acid exhibits characteristic features arising from two types of ligand $\rightarrow$ metal charge-transfer bands involving different oxygen atoms. The Keggin unit comprises twelve terminal oxygen atoms $\left(\mathrm{O}_{\mathrm{t}}\right)$ coordinated to tungsten, while each oxygen atom from the central $\mathrm{PO}_{4}$ tetrahedron $\left(\mathrm{O}_{\mathrm{c}}\right)$ is bonded to three different tungsten atoms. There are also two types of bridging oxygen; twelve bridged between the four different $\mathrm{W}_{3} \mathrm{O}_{13}$ sub-units $\left(\mathrm{O}_{\mathrm{b} 1}\right)$ in which each sub-unit comprises three $\mathrm{WO}_{6}$ connected by three other oxygen atoms $\left(\mathrm{O}_{\mathrm{b} 2}\right)$ resulting in a total of $24 \mathrm{O}$ bridging atoms (Fig. S3a). PTA therefore possesses four unique oxygen species. Characteristic charge-transfer bands were observed in the spectrum of phosphotungstic acid at 213 and $266 \mathrm{~nm}$ (Fig. S3b): that around $213 \mathrm{~nm}$ is assigned to $\mathrm{O}_{\mathrm{t}} \rightarrow \mathrm{W}$ LMCT (ligand-to-metal-charge-transfer) and that around $266 \mathrm{~nm}$ is assigned to $\mathrm{O}_{\mathrm{b} 1}$, $\mathrm{b}_{2} \rightarrow \mathrm{W}$ LMCT band $[52,53]$. 
The PTA loading was quantified from the intensity of the $266 \mathrm{~nm}$ absorption band following the suspension of $1.0 \mathrm{~g}$ of $\mathrm{Fe}_{3} \mathrm{O}_{4} / \mathrm{EN}-\mathrm{MIL}-101$ in a $20 \mathrm{~mL}$ methanolic solution of PTA (initial concentration $5 \times 10^{4} \mathrm{ppm}$ ) and stirred at ambient temperature for $6 \mathrm{~h}$ to equilibrate adsorption on the MOF. The resulting UV-Vis spectrum of the diluted sample after magnetic separation from the solution was compared with calibration curves for PTA solutions, and indicated a PTA loading of $21 \mathrm{wt} \%(6.2 \mathrm{~mol} \%)$ on the MOF, close to that of $16.9 \mathrm{wt} \%$ determined by ICP-OES.

Fourier transform infrared (FT-IR) spectra of MIL-101, EN-MIL-101, $\mathrm{Fe}_{3} \mathrm{O}_{4} / \mathrm{EN}-\mathrm{MIL}-$ 101, and PTA@ $\mathrm{Fe}_{3} \mathrm{O}_{4} / \mathrm{EN}-\mathrm{MIL}-101$ are shown in Fig. S4. MIL-101 exhibited bands around 3432 and $1627 \mathrm{~cm}^{-1}$ associated with water. The band at $1666 \mathrm{~cm}^{-1}$ was due to the presence of DMF guest molecules, while bands at 1404 and $1546 \mathrm{~cm}^{-1}$ corresponded to the symmetric and asymmetric $\mathrm{O}-\mathrm{C}-\mathrm{O}$ stretching vibrations of carboxylates in the MOF framework $[54,55]$. The $\mathrm{C}=\mathrm{C}$ stretching vibration of the aromatic ring in terephthalic acid was observed at $1504 \mathrm{~cm}^{-1}$. The other bands around 1168, 1103, 883 and $748 \mathrm{~cm}^{-1}$ can be attributed to C-H deformations [55]. In the spectrum of as-synthesized EN-MIL-101, both N-H stretches spanning 3100-3600 $\mathrm{cm}^{-1}$ exhibited changes relative to the parent MIL-101 spectrum, while the C-H stretches between 2890 and $2950 \mathrm{~cm}^{-1}$ indicated the presence of framework ethylenediamine [56, 57]. Following iron oxide functionalization, a band characteristic of $\mathrm{Fe}_{3} \mathrm{O}_{4}$ appeared at $580 \mathrm{~cm}^{-1}$ evidencing the incorporation of magnetic nanoparticles into MIL-101 consistent with XRD $[58,59]$. The $\left[\mathrm{PW}_{12} \mathrm{O}_{40}\right]^{3-}$ Keggin anion exhibits four characteristic bands arising from $v_{\text {as }}(\mathrm{P}-$ $\left.\mathrm{O}_{\mathrm{a}}\right), v_{\mathrm{as}}\left(\mathrm{W}-\mathrm{O}_{\mathrm{t}}\right), v_{\mathrm{as}}\left(\mathrm{W}-\mathrm{O}_{\mathrm{b} 1}\right)$ and $v_{\mathrm{as}}\left(\mathrm{W}-\mathrm{O}_{\mathrm{b} 2}\right)$ vibrations [60]. The latter three are apparent at 983 , 891 and $806 \mathrm{~cm}^{-1}$ in the spectrum of PTA@ $@ \mathrm{Fe}_{3} \mathrm{O}_{4} / \mathrm{EN}-\mathrm{MIL}-101$, while the $v_{\mathrm{as}}\left(\mathrm{P}-\mathrm{O}_{\mathrm{a}}\right)$ band appears split into two bands at 1080 and $1053 \mathrm{~cm}^{-1}$, possibly due to formation of the lacunary species $\left[\mathrm{PW}_{11} \mathrm{O}_{39}\right]^{7-}$ species [61]. The appearance of phosphotungstic acid characteristic bands in the FT-IR spectrum of PTA@ $\mathrm{Fe}_{3} \mathrm{O}_{4} / \mathrm{EN}-\mathrm{MIL}-101$ confirms that the primary Keggin structure of the heteropolyacid was retained after immobilization.

For the parent MIL-101, the Cr 2p XP spectrum showed a doublet with $2 \mathrm{p}_{3 / 2}$ binding energy of $575.6 \mathrm{eV}$ (Fig. 5a) characteristic of the expected $\mathrm{Cr}^{3+}$ vertex species [62]. Ethylenediamine functionalization resulted in the appearance of a $\mathrm{N}$ 1s chemical environment at $399.0 \mathrm{eV}$ binding energy (Fig. 5b), consistent with amine incorporation [62]. This was accompanied by an increase in $\mathrm{Cr} 2 \mathrm{p}$ energy to $576.7 \mathrm{eV}$, indicating direct coordination between the diamine and $\mathrm{Cr}^{3+}$ sites. Subsequent iron oxide addition had minimal impact on either $\mathrm{Cr} 2 \mathrm{p}$ or $\mathrm{N} 1 \mathrm{~s}$ environments, suggesting only weak interactions between $\mathrm{Fe}_{3} \mathrm{O}_{4}$ nanoparticles and the amine-functionalized MOF framework, with a Fe $2 p$ doublet $710.5 \mathrm{eV}$ 
consistent with magnetite (Fig. 5c) [62]. The tungsten 4f XP spectrum of PTA@ $\mathrm{Fe}_{3} \mathrm{O}_{4} / \mathrm{EN}-$ MIL-101 (Fig. 5d) revealed a doublet with $\mathrm{W} 4 \mathrm{f}_{7 / 2}$ binding energy of $35.6 \mathrm{eV}$ and spin-orbit splitting of $2.14 \mathrm{eV}$ consistent with that of silica supported $\mathrm{H}_{3} \mathrm{PW}_{12} \mathrm{O}_{40}(35.3 \mathrm{eV})$ [48] and hence retention of the Keggin structure. Note that silica supported PTA exhibits two distinct chemical environments [48]: a minority component arising from three terminal $\mathrm{W}=\mathrm{O}$ units directly coordinated (probably via hydrogen bonding to silanols) to silica giving rise to a low binding energy doublet at $33.5 \mathrm{eV}$; and a majority component arising from nine terminal $\mathrm{W}=\mathrm{O}$ units unperturbed by the silica surface (characteristic of the parent PTA) at $35.3 \mathrm{eV}$. If PTA Keggin units coordinate to ethylenediamine within the MIL-101 pore network via a single $\mathrm{W}=\mathrm{O}$ unit then only $1 / 12^{\text {th }}$ of the $\mathrm{W}$ atoms would be perturbed relative to the parent acid, and hence the W $4 \mathrm{f}$ XP spectrum would be dominated by the high binding energy environment giving rise to a $4 f_{7 / 2}$ envelope centred at $35.3 \mathrm{eV}$ as seen in Fig. 5d. PTA incorporation had no impact on the $\mathrm{Cr}$ or Fe chemical environments as expected, however the $\mathrm{N} 1 \mathrm{~s}$ peak shifted from 399.0 to $399.9 \mathrm{eV}$, confirming coordination of the heteropolyacid to the amine linker. 

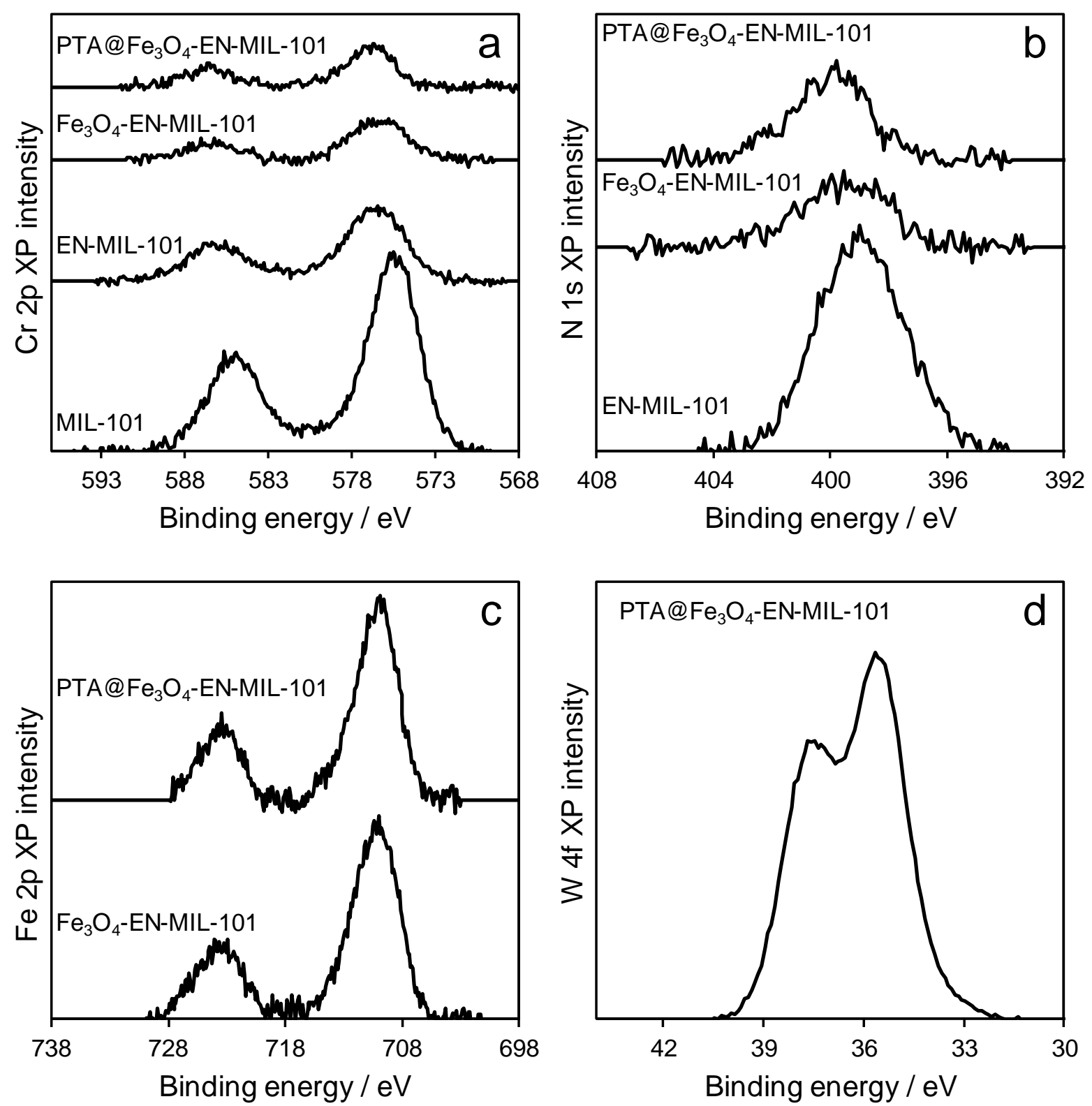

Fig. 5. Background-subtracted XP spectra of MIL-101, EN-MIL-101, $\mathrm{Fe}_{3} \mathrm{O}_{4} / \mathrm{EN}-\mathrm{MIL}-101$, and PTA@ $\mathrm{Fe}_{3} \mathrm{O}_{4} / \mathrm{EN}-\mathrm{MIL}-101$.

The thermal stability of MIL-101, EN-MIL-101, $\mathrm{Fe}_{3} \mathrm{O}_{4} / \mathrm{EN}-\mathrm{MIL}-101$, and PTA@ $\mathrm{Fe}_{3} \mathrm{O}_{4} / \mathrm{EN}-\mathrm{MIL}-101$ was assessed by TGA-DTA (Fig. 6). The resulting DTA profiles only exhibited exothermic peaks below $400{ }^{\circ} \mathrm{C}$. The TGA profile of MIL-101 showed two major mass losses in the range of $25-300{ }^{\circ} \mathrm{C}$ and $300-500{ }^{\circ} \mathrm{C}$. The first is attributed to the loss of guest water molecules and DMF from the larger mesopore cage of MIL-101(Cr) below 200 ${ }^{\circ} \mathrm{C}[44,63]$ and that between $200-300{ }^{\circ} \mathrm{C}$ from the smaller mesoporous cage $[54,55]$ Higher temperature loss is attributed to collapse of the MIL-101 framework between $300-500{ }^{\circ} \mathrm{C}$ due to composition of the dicarboxylate linkers and $\mathrm{OH}$ elimination [15, 44]. MIL-101(Cr) thus 
appears thermally stable to $300{ }^{\circ} \mathrm{C}$ in accordance with the literature report of $\mathrm{Xu}$ et al [64], with a total mass loss approaching $90 \%$ by $800{ }^{\circ} \mathrm{C}$. The TGA-DTA profiles of EN-MIL-101 were similar pattern to the parent MOF, but with a $12 \%$ greater overall mass loss reflecting the additional organic (ethylenediamine) functionality present. $\mathrm{Fe}_{3} \mathrm{O}_{4} / \mathrm{EN}-\mathrm{MIL}-101$ exhibited a similar pattern to MIL-101 and EN-MIL-101, albeit in this instance a lower mass loss ( 58 \% total) due to the presence of dense, inorganic $\mathrm{Fe}_{3} \mathrm{O}_{4}$ nanoparticles. PTA incorporation into the $\mathrm{Fe}_{3} \mathrm{O}_{4} / \mathrm{EN}-\mathrm{MIL}-101$ further decreased the total mass loss to only $40 \%$ due to the incorporation of additional thermally stable (inorganic) components and associated displacement of in-pore (thermally unstable) solvent guest molecules. These changes mirror the decrease in bulk $\mathrm{C}$ content (from elemental analysis), which fell from $31 \mathrm{wt} \%$ for MIL-101 to $12 \mathrm{wt} \%$ for $\mathrm{Fe}_{3} \mathrm{O}_{4}$ EN-MIL-101 (for which the Fe loading was $37 \mathrm{wt} \%$ ), and reached only 9 wt $\%$ for PTA@ $\mathrm{Fe}_{3} \mathrm{O}_{4}$-EN-MIL-101.

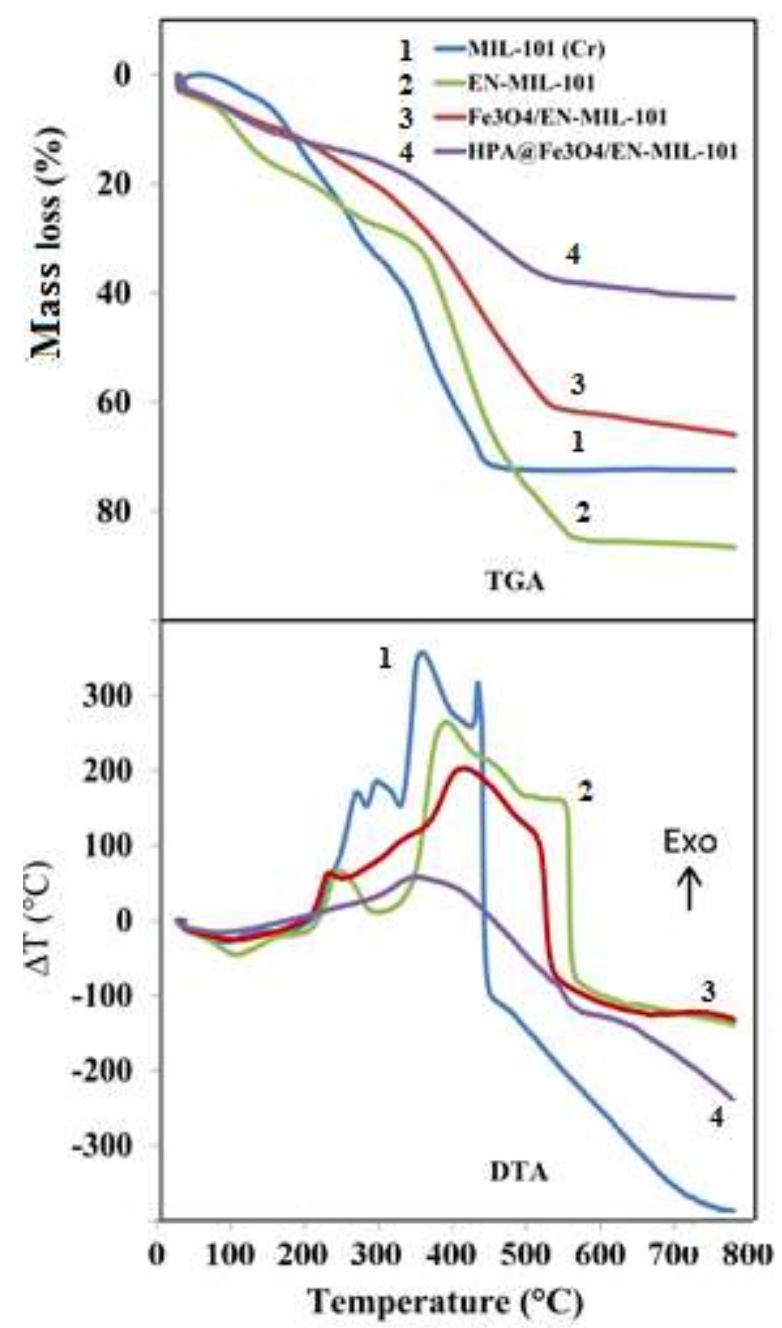

Fig. 6. TGA-DTA curves of MIL-101, EN-MIL-101, $\mathrm{Fe}_{3} \mathrm{O}_{4} / \mathrm{EN}-\mathrm{MIL}-101$, and PTA $@ \mathrm{Fe}_{3} \mathrm{O}_{4} / \mathrm{EN}-\mathrm{MIL}-$ 101. 


\subsection{Catalytic tests}

The effect of reaction temperature was first examined to optimize the catalytic activity of PTA@ $\mathrm{Fe}_{3} \mathrm{O}_{4} / \mathrm{EN}-\mathrm{MIL}-101$ for the condensation of benzaldehyde, phthalhydrazide, and dimedone (Fig. 7a). The reaction was slow at room temperature, resulting in only $55 \%$ isolated product yield after $140 \mathrm{~min}$, whereas at $60{ }^{\circ} \mathrm{C}$ a $79 \%$ yield was attained after 75 min, with 94 $\%$ yield obtained at $100{ }^{\circ} \mathrm{C}$ after only 20 min reaction. Further temperature increases had no impact on activity. The effect of reaction time at the optimum temperature $\left(100{ }^{\circ} \mathrm{C}\right)$ was subsequently examined to determine the minimum reaction time to reach optimal yield (Fig. 7b), with 20 min required to reach the limiting $94 \%$ conversion.

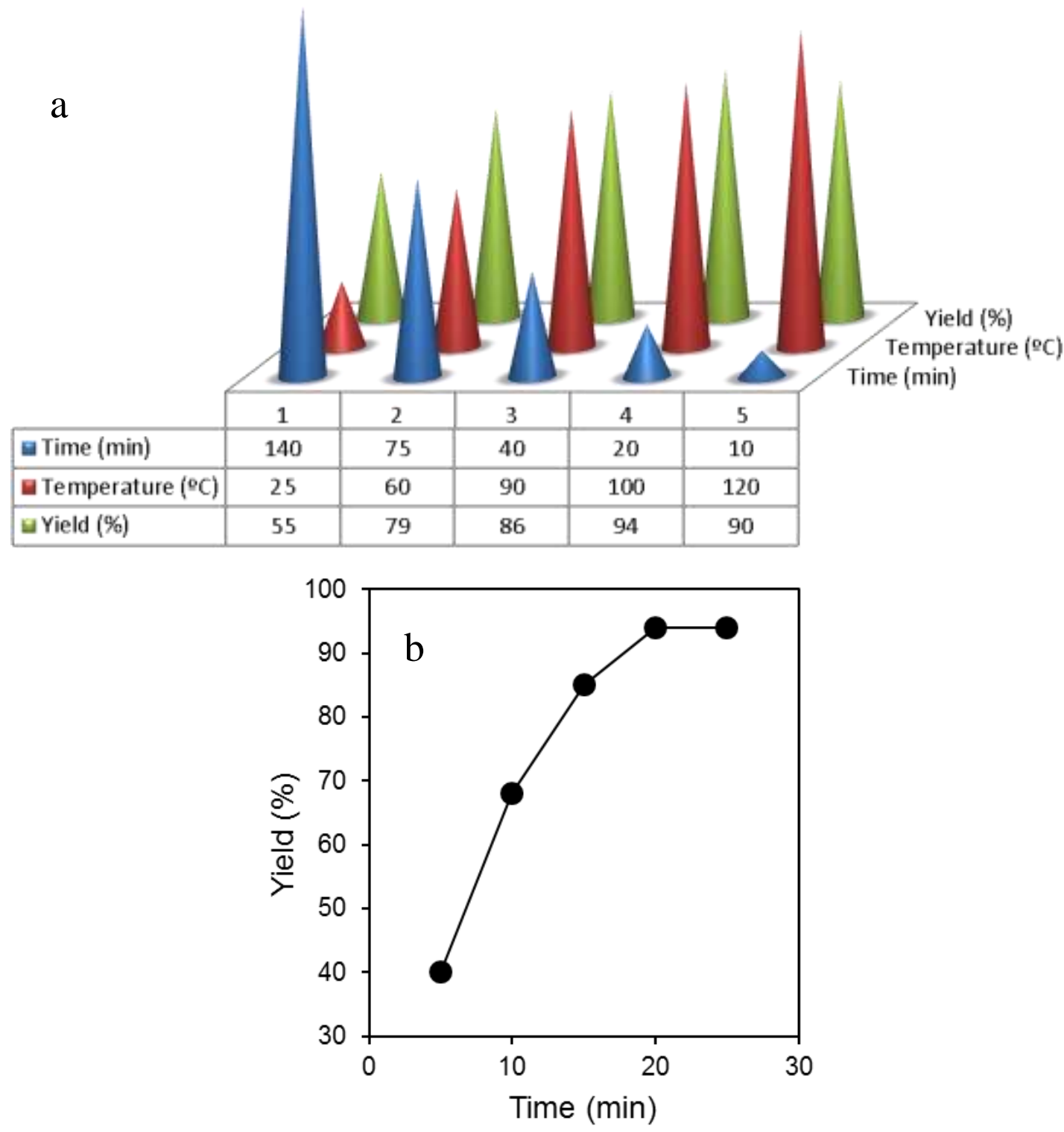

Fig. 7. (a) Effect of reaction temperature, and (b) effect of reaction time on catalytic synthesis of 2,2dimethyl-13-phenyl-2,3-dihydro-1H-indazolo[2,1-b]phthalazine-4,6,11(13H)-trione with PTA@ $\mathrm{Fe}_{3} \mathrm{O}_{4} / \mathrm{EN}-\mathrm{MIL}-101$. Reaction condition is described in 2.6. 
The mass of PTA@ $\mathrm{Fe}_{3} \mathrm{O}_{4} / \mathrm{EN}-\mathrm{MIL}-101$ was then optimized employing the reaction temperature and time identified above (Fig. S5). A maximum yield of $94 \%$ was obtained for $0.02 \mathrm{~g}$ of PTA@ $\mathrm{Fe}_{3} \mathrm{O}_{4} / \mathrm{EN}-\mathrm{MIL}-101$ (representing only $4 \mathrm{mg}$ of $\mathrm{H}_{3} \mathrm{PW}_{12} \mathrm{O}_{40}$ ) in $20 \mathrm{~min}$, highlighting the efficacy of PTA@ $\mathrm{Fe}_{3} \mathrm{O}_{4} / \mathrm{EN}-\mathrm{MIL}-101$ for this condensation reaction.

\subsection{Impact of catalyst components}

The impact of each component of the PTA@ $\mathrm{Fe}_{3} \mathrm{O}_{4} / \mathrm{EN}-\mathrm{MIL}-101$ catalyst on reactivity was subsequently assessed for the condensation reaction (Fig. 8). Lewis acidic $\mathrm{Fe}_{3} \mathrm{O}_{4}$ showed modest activity (44\% yield), comparable to the Lewis acidic MIL-101 and mixed Lewis acid/Brønsted basic EN-MIL-101 supports, which gave 59 and $54 \%$ yields respectively after 20 min. In contrast, the (homogeneous) pure Brønsted acid PTA offered $67 \%$ yield. The combination of Lewis and Brønsted acidity in the PTA@ $@ \mathrm{Fe}_{3} \mathrm{O}_{4} / \mathrm{EN}-\mathrm{MIL}-101$ composite significantly enhanced activity above that achievable with either individual acid, delivering a 94\% yield.

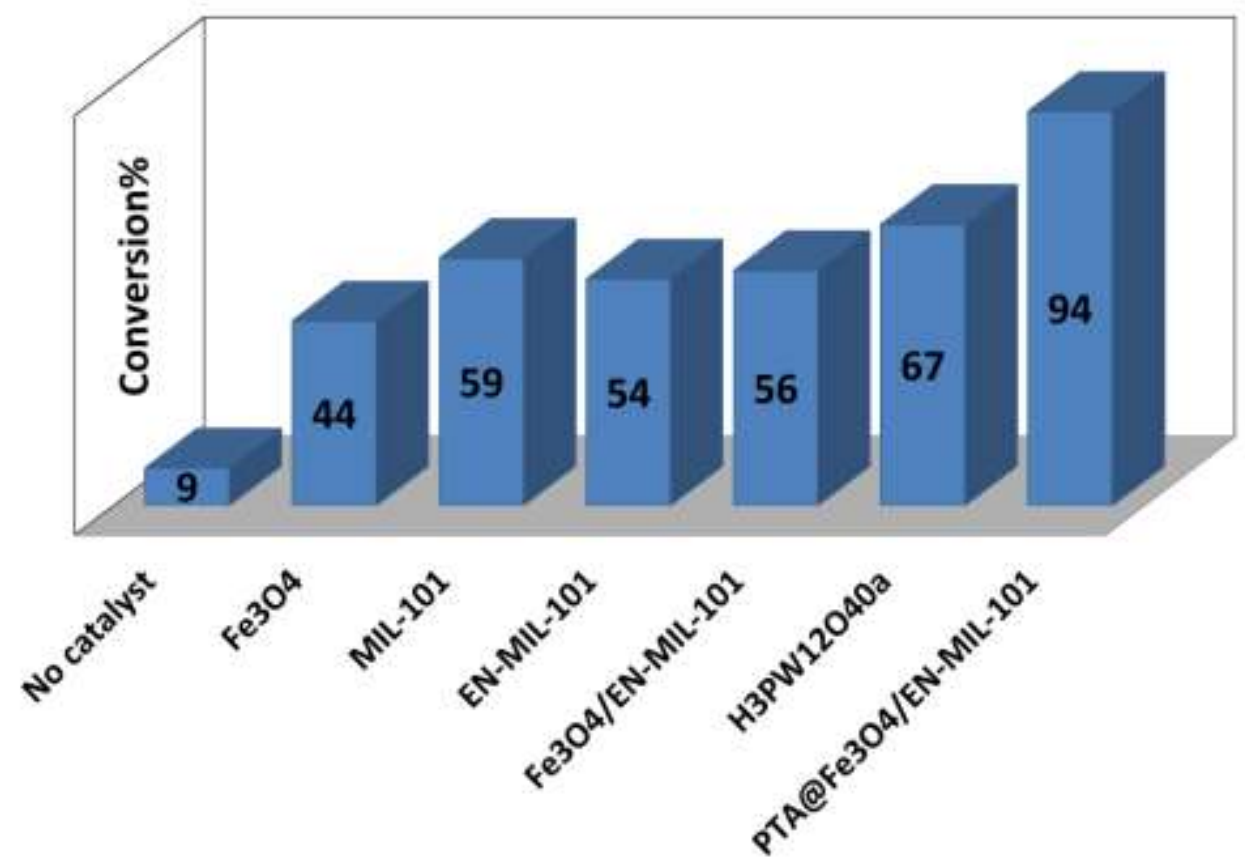

Fig. 8. Effect of catalyst components on isolated product yields. Reaction condition given in the footnote to Table 1. 


\subsection{Phthalhydrazide and benzaldehyde condensation with diverse diketones}

Phthalhydrazide and aromatic aldehyde condensation with a range of cyclic and acyclic diketones was subsequently explored catalyzed by PTA@ $\mathrm{Fe}_{3} \mathrm{O}_{4} / \mathrm{EN}-\mathrm{MIL}-101$. Among the investigated diketones (Table 1), dimedone (5,5-dimethyl-1,3-cyclohexane-dione) gave the highest product yield. The electron releasing nature of the two methyl substituents in dimedone appears desirable to activate the diketone for this condensation reaction [65, 66]. The linear hexanediones (2, 5-hexane-dione and 3, 4-hexane-dione) were less efficient than their cyclic counterpart, resulting in lower product yields of 52-69\% after $40 \mathrm{~min}$.

Table 1. Reactivity of PTA@ $\mathrm{Fe}_{3} \mathrm{O}_{4} / \mathrm{EN}-\mathrm{MIL}-101$ for one-pot condensation

2,5-hexane-dione

Reaction conditions: Aldehyde $(0.25 \mathrm{mmol})$, phthalhydrazide $(0.25 \mathrm{mmol})$ and dimedone $(0.25 \mathrm{mmol})$, catalyst $(0.02 \mathrm{~g})$ at $100^{\circ} \mathrm{C}$. Yields determined by TLC. Work-up performed as described in Experimental.

\subsection{Benchmarking of PTA@ $@ \mathrm{Fe}_{3} \mathrm{O}_{4} / \mathrm{EN}-\mathrm{MIL}-101$ against literature}

Table 2 provides a semi-quantitative comparison of the performance of PTA @ $\mathrm{Fe}_{3} \mathrm{O}_{4} / \mathrm{EN}-\mathrm{MIL}$ 101 catalyst with several literature catalyst systems for the reaction of dimedone, phthalhydrazide, and benzaldehyde as a representative model reaction. Although the wide variation in catalyst:reactant stoichiometries employed in the literature, and lack of detailed 
information on the acid site loading of each catalyst in Table 2 hinders a quantitative comparison, it is clear that PTA@ $@ \mathrm{Fe}_{3} \mathrm{O}_{4} / \mathrm{EN}-\mathrm{MIL}-101$ outperforms all but entry 4 in Table 2 for which catalyst recovery/re-use is difficult due to leaching of sulfonic acid groups. The heterogeneous nature of the present Lewis/Brönsted acid catalyst supported on a magnetic MIL-101 nanostructure is in line with the efforts on the development of new eco-compatible strategies for the synthesis of $2 \mathrm{H}$-indazolo[2,1-b]phthalazine-1,6,11(13H)-trione derivatives, and offers facile product separation and catalyst recycling in contrast to entries 1-3.

Table 2. Catalytic performance of PTA@ $@ \mathrm{Fe}_{3} \mathrm{O}_{4}$ EN-MIL-101 against literature catalysts

\begin{tabular}{|c|c|c|c|c|c|c|}
\hline Entry & Catalyst and conditions & $\begin{array}{c}\text { Catalyst } \\
\text { mass } \\
(\mathrm{mg})\end{array}$ & $\begin{array}{l}\text { Time } \\
\text { (min) }\end{array}$ & $\begin{array}{c}\text { Aldehyde } \\
\text { Amount } \\
\text { (mmol) }\end{array}$ & $\begin{array}{l}\text { Yield } \\
(\%)\end{array}$ & Ref. \\
\hline 1 & $\begin{array}{l}\text { Ceric ammonium nitrate, solvent- } \\
\text { free, } 50^{\circ} \mathrm{C}\end{array}$ & 27 & 120 & 1 & 94 & {$[67]$} \\
\hline 2 & $\begin{array}{l}\text { p-toluenesulfonic acid (p-TSA), } \\
\text { solvent-free, } 80^{\circ} \mathrm{C}\end{array}$ & 52 & 10 & 1.2 & 86 & {$[68]$} \\
\hline 3 & $\begin{array}{l}{\left[\left[\left(\mathrm{CH}_{2}\right)_{4} \mathrm{SO}_{3} \mathrm{HMIM}\right]\left[\mathrm{HSO}_{4}\right],\right.} \\
\text { solvent-free, } 100{ }^{\circ} \mathrm{C}\end{array}$ & 47 & 10 & 1 & 81 & [69] \\
\hline 4 & $\begin{array}{l}\text { Silica sulfuric acid, solvent-free, } \\
100{ }^{\circ} \mathrm{C}\end{array}$ & 25 & 8 & 12 & 87 & {$[70]$} \\
\hline 5 & $\begin{array}{l}\mathrm{Fe}_{3} \mathrm{O}_{4} @ \text { silica sulfuric acid, solvent- } \\
\text { free, } 100{ }^{\circ} \mathrm{C}\end{array}$ & 75 & 35 & 1 & 88 & {$[71]$} \\
\hline 6 & $\begin{array}{l}\mathrm{PTA} @ \mathrm{Fe}_{3} \mathrm{O}_{4} / \mathrm{EN}-\mathrm{MIL}-101, \\
\text { solvent-free, } 100^{\circ} \mathrm{C}\end{array}$ & 20 & 20 & 1 & 94 & $\begin{array}{l}\text { This } \\
\text { work }\end{array}$ \\
\hline
\end{tabular}

In each case, the optimum reaction condition is stated.

\subsection{Synthesis of different phthalazine-triones}

Following optimization of the reaction conditions, the substrate scope of PTA@ $\mathrm{Fe}_{3} \mathrm{O}_{4} / \mathrm{EN}$ MIL-101 was explored for various aromatic aldehydes in the preparation of diverse substituted 2H-indazolo [2, 1-b]phthalazine-triones. Ortho-, meta-, and para-substituted aryl aldehydes all gave the corresponding $2 \mathrm{H}$-indazolo $[2,1-\mathrm{b}]$ phthalazine-trione derivatives in good $\rightarrow$ excellent yields (Table 3). High yields were obtained for aldehydes possessing electron-withdrawing 
and with electron-donating substituents. Aromatic aldehydes were more reactive than aliphatic analogues which gave poor yields even over longer reaction times.

Table 3 Synthesis of different 2H-indazolo[2,1-b]phthalazine-1,6,11(13H)-triones

\begin{tabular}{ccccc}
\hline Entry & $\mathrm{R}_{1}$ & $\mathrm{R}$ & Time (min) & Yield (\%) \\
\hline 1 & $\mathrm{Ph}$ & $\mathrm{Me}$ & 20 & 94 \\
2 & $4-\mathrm{Br}-\mathrm{ph}$ & $\mathrm{Me}$ & 60 & 60 \\
3 & $4-\mathrm{NO}_{2}-\mathrm{Ph}$ & $\mathrm{Me}$ & 80 & 50 \\
4 & $2-\mathrm{Cl}-\mathrm{Ph}$ & $\mathrm{Me}$ & 40 & 65 \\
5 & $2,6-(\mathrm{Cl})_{2}-\mathrm{Ph}$ & $\mathrm{Me}$ & 60 & 70 \\
7 & $4-(\mathrm{CH})_{2} \mathrm{~N}-\mathrm{Ph}$ & $\mathrm{Me}$ & 80 & 81 \\
8 & $4-\mathrm{Me}-\mathrm{Ph}$ & $\mathrm{Me}$ & 60 & 70 \\
9 & Pyridinecarbaldehyde & $\mathrm{Me}$ & 40 & 22 \\
10 & terephthalaldehyde & $\mathrm{Me}$ & 60 & 10 \\
11 & Butyraldehyde & $\mathrm{Me}$ & 60 & 24
\end{tabular}

Yields refer to the isolated pure products. The desired pure products were characterized by comparison of their physical data with those of known compounds [65].

\subsection{Leaching test}

To ensure that the catalytic activity was only generated from immobilized functions within PTA@ $\mathrm{Fe}_{3} \mathrm{O}_{4} / \mathrm{EN}-\mathrm{MIL}-101$, and not from PTA leached during reaction, a hot filtration test was conducted. The condensation reaction was performed at $100{ }^{\circ} \mathrm{C}$ for $10 \mathrm{~min}$ in the presence of the PTA@ $@ \mathrm{Fe}_{3} \mathrm{O}_{4} / \mathrm{EN}-\mathrm{MIL}-101$ catalyst, at which stage the product yield has reached $68 \%$ compared with $94 \%$ after $20 \mathrm{~min}$ ). The catalyst was then magnetically-separated from the hot supernatant which was immediately decanted, and the latter monitored for another $10 \mathrm{~min}$, however the product yield remained at $68 \%$. This result confirmed that condensation was catalyzed solely by the heterogeneous solid acid.

\subsection{Recyclability of PTA@ @ $\mathrm{Fe}_{3} \mathrm{O}_{4} / \mathrm{EN}-\mathrm{MIL}-101$}

The reusability of the catalyst was arranged to be tested in the synthesis of 2,2-dimethyl-13phenyl-2,3-dihydro-1H-indazolo[2,1-b]phthalazine-4,6,11(13H)-trione, as shown in Fig. 9, 
employing magnetic separation of the catalyst and subsequent ethanol washing and drying at $90{ }^{\circ} \mathrm{C}$ for $4 \mathrm{~h}$ in between each reaction. The product yield (and hence catalytic activity) remained almost constant over eight consecutive reactions, demonstrating excellent stability, reflecting the relatively mild, and crucially solvent free, reaction conditions. Deactivation of supported heteropolyacids most commonly arises from their leaching in polar media [72], which is minimised in this work by the absence of solvent and low reactant polarity. Powder XRD of the spent catalyst confirmed negligible structural changes to the MOF framework following one reaction (Fig. S6).

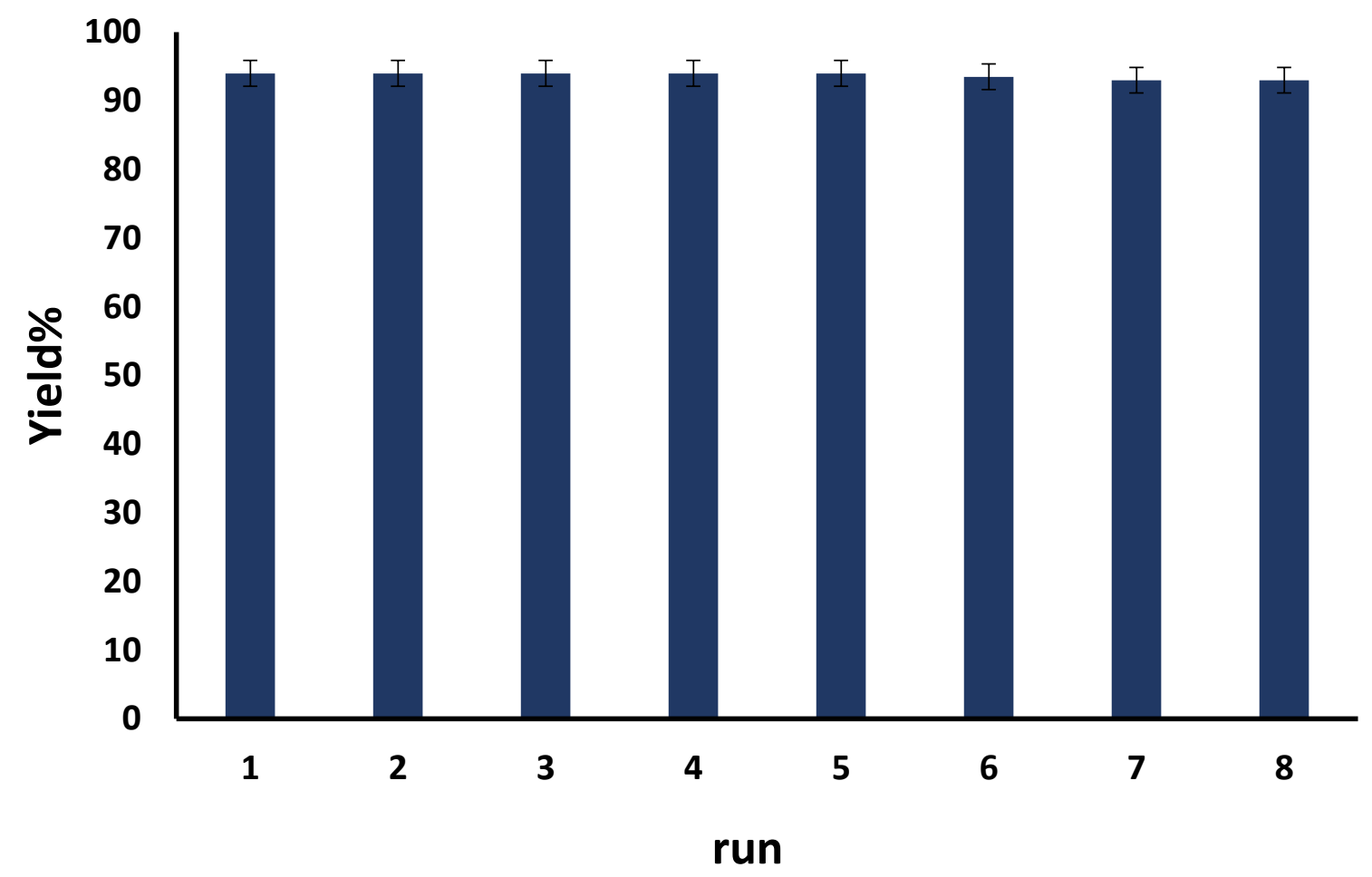

Fig. 9. Product yield as a function of reusability of PTA@ $@ \mathrm{Fe}_{3} \mathrm{O}_{4} / \mathrm{EN}-\mathrm{MIL}-101$ catalyst.

\subsection{Proposed reaction pathway for a heterogeneous catalytic system}

In agreement with the literature, the following mechanism, as shown in Scheme 2, is suggested for the formation of $2 \mathrm{H}$-indazolo [2,1-b]phthalazine-triones. At the beginning, it was started by a Knoevenagel condensation reaction of 1,3-dione and the aldehyde which subsequently pursued by a Michael addition of phthalhydrazide, and later cyclization. The catalyst activity was interpreted by donating $\mathrm{H}^{+}$from the heteropolyacid and Lewis acid sites on $\mathrm{Fe}_{3} \mathrm{O}_{4}$ and MIL101 fragments which was initially bound to the carbonyl oxygen of the aldehyde. Finally, (I) was generated by nucleophilic addition of dimedone to the carbonyl group of aldehyde and provoked by loss of $\mathrm{H}_{2} \mathrm{O}$ which affords (II) $[65,73]$. 
<smiles>[R]c1ccc([R])c(C=O)c1</smiles>

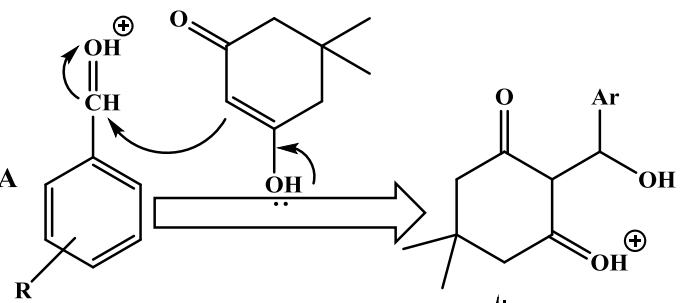<smiles>C1CC1C1CC1</smiles>

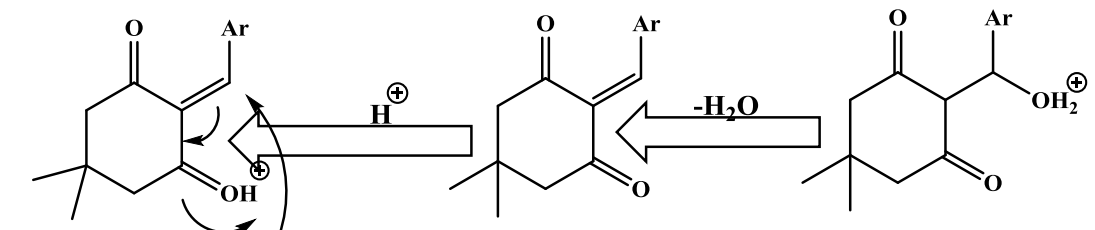

(II)

(I)

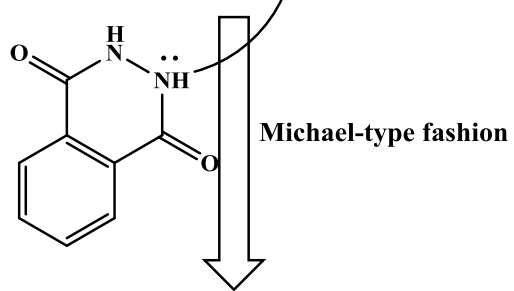

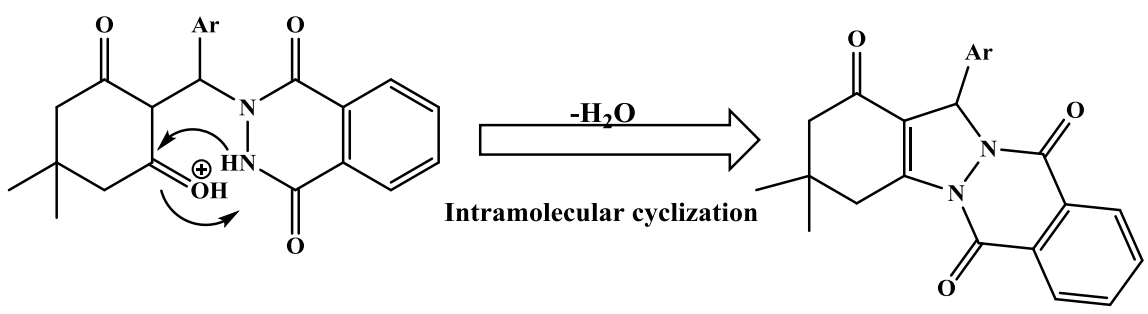

Scheme 2. Proposed mechanism for the synthesis of $2 H$-indazolo[1,2-b]phthalazine-triones.

\section{Conclusions}

A magnetically-separable heterogeneous catalyst, PTA@ $\mathrm{Fe}_{3} \mathrm{O}_{4} / \mathrm{EN}-\mathrm{MIL}-101$ was prepared and characterized by bulk and surface sensitive analytical methods, comprising $\mathrm{Fe}_{3} \mathrm{O}_{4}$ nanoparticles (likely distributed over the external surfaces of MOF crystallites) and phosphotungstic acid Keggin units uniformly distributed throughout the pore network tethered to amine linkers which themselves coordinate to Lewis acid $\mathrm{Cr}^{3+}$ vertices. This catalyst was investigated for the one-pot synthesis of $2 \mathrm{H}$-indazolo[2,1-b]phthalazine-1,6,11(13H)-trione derivatives, exhibiting excellent activity and stability, and good to excellent yields under mild 
and environmentally benign (solventless) conditions. This catalyst, and design strategy, afford new and green routes to pharmacologically important $2 \mathrm{H}$-indazolo[2,1-b]phthalazine-triones.

\section{Acknowledgements}

Partial financial support of the Research Councils of Shahid Beheshti and Hakim Sabzevari Universities is greatly acknowledged.

\section{References}

[1] A.H. Chughtai, N. Ahmad, H.A. Younus, A. Laypkov, F. Verpoort, Chem Soc Rev, 44 (2015) 6804-6849.

[2] L. Oar-Arteta, T. Wezendonk, X. Sun, F. Kapteijn, J. Gascon, Mater. Chem. Front., (2017).

[3] M. Zhao, S. Ou, C.D. Wu, Accounts of chemical research, 47 (2014) 1199-1207.

[4] S.-N. Zhao, X.-Z. Song, S.-Y. Song, H.-j. Zhang, Coordination Chemistry Reviews, 337 (2017) 80-96.

[5] K. Dhanalaxmi, R. Singuru, S. Mondal, L. Bai, B.M. Reddy, A. Bhaumik, J. Mondal, ACS Sustainable Chemistry \& Engineering, (2016).

[6] H. Arandiyan, J. Scott, Y. Wang, H. Dai, H. Sun, R. Amal, ACS Applied Materials \& Interfaces, 8 (2016) 2457-2463.

[7] G. Ngnie, G.K. Dedzo, C. Detellier, Dalton Transactions, 45 (2016) 9065-9072.

[8] W. Xuan, C. Zhu, Y. Liu, Y. Cui, Chemical Society Reviews, 41 (2012) 1677-1695.

[9] A.U. Czaja, N. Trukhan, U. Muller, Chemical Society Reviews, 38 (2009) 1284-1293.

[10] Y.K. Hwang, D.-Y. Hong, J.-S. Chang, S.H. Jhung, Y.-K. Seo, J. Kim, A. Vimont, M. Daturi, C. Serre, G. Férey, Angewandte Chemie International Edition, 47 (2008) 4144-4148.

[11] B. Li, Y. Zhang, D. Ma, L. Li, G. Li, G. Li, Z. Shi, S. Feng, Chemical Communications, 48 (2012) 6151-6153.

[12] P.D.C. Dietzel, V. Besikiotis, R. Blom, Journal of Materials Chemistry, 19 (2009) 7362-7370.

[13] J. Lee, O.K. Farha, J. Roberts, K.A. Scheidt, S.T. Nguyen, J.T. Hupp, Chemical Society

Reviews, 38 (2009) 1450-1459.

[14] P. Valvekens, F. Vermoortele, D. De Vos, Catalysis Science \& Technology, 3 (2013) 1435-1445.

[15] D.-Y. Hong, Y.K. Hwang, C. Serre, G. Férey, J.-S. Chang, Advanced Functional Materials, 19 (2009) 1537-1552.

[16] M. Kurmoo, Chemical Society Reviews, 38 (2009) 1353-1379.

[17] X. Zhao, S. Liu, Z. Tang, H. Niu, Y. Cai, W. Meng, F. Wu, J.P. Giesy, Scientific Reports, 5

(2015) 11849.

[18] M. Sapna, in, Thapar University, Patiala, 2009.

[19] P.J. Dunn, Chemical Society Reviews, 41 (2012) 1452-1461.

[20] P.J. Dunn, Green Chemistry, 15 (2013) 3099-3104.

[21] J.L. Tucker, M.M. Faul, Nature, 534 (2016) 27-29.

[22] M. Asif, International Journal of Pharmaceutical Chemistry, 5 (2016) 397-409.

[23] M. Hegde, K. Mantelingu, H.A. Swarup, C.S. Pavankumar, I. Qamar, S.C. Raghavan, K.S.

Rangappa, RSC Advances, 6 (2016) 6308-6319.

[24] M. Asif, Current Medicinal Chemistry, 19 (2012) 2984-2991.

[25] B. Dam, M. Saha, R. Jamatia, A. Pal, Synfacts, 12 (2016) 0992-0992.

[26] B. Dam, M. Saha, R. Jamatia, A.K. Pal, RSC Advances, 6 (2016) 54768-54776.

[27] F. Davod, A. R Kiasat, M. Enjilzadeh, M. Cheraghchi, Letters in Organic Chemistry, 13 (2016) 58-66.

[28] M. Nikoorazm, A. Ghorbani-Choghamarani, M. Khanmoradi, RSC Advances, 6 (2016) 5654956561.

[29] R.H. Vekariya, N.P. Prajapati, H.D. Patel, Synthetic Communications, 46 (2016) 197-219.

[30] H. Zhang, J. Deng, Y. Wu, ACS Sustainable Chemistry \& Engineering, (2016). 
[31] L.L. Chng, N. Erathodiyil, J.Y. Ying, Accounts of chemical research, 46 (2013) 1825-1837.

[32] S. Li, F. Huo, Nanoscale, 7 (2015) 7482-7501.

[33] Z. Tai, M.A. Isaacs, C.M.A. Parlett, A.F. Lee, K. Wilson, Catalysis Communications, 92 (2017) $56-60$.

[34] R. Tayebee, S. Tizabi, Chinese Journal of Catalysis, 33 (2012) 962-969.

[35] R. Tayebee, N. Abdollahi, M. Ghadamgahi, Journal of the Chinese Chemical Society, 60 (2013) 1014-1018.

[36] R. Tayebee, M.M. Amini, F. Nehzat, O. Sadeghi, M. Armaghan, Journal of Molecular Catalysis A: Chemical, 366 (2013) 140-148.

[37] R. Tayebee, M.M. Amini, H. Rostamian, A. Aliakbari, Dalton Transactions, 43 (2014) 15501563.

[38] B. Maleki, M. Baghayeri, S.A. Jannat Abadi, R. Tayebee, A. Khojastehnezhad, RSC Advances, 6 (2016) 96644-96661.

[39] R. Tayebee, K. Savoji, M.K. Razi, B. Maleki, RSC Advances, 6 (2016) 55319-55326.

[40] H.R. Shaterian, A. Hosseinian, M. Ghashang, Arkivoc, 2 (2009) 59-67.

[41] M. Kidwai, A. Jahan, R. Chauhan, N.K. Mishra, Tetrahedron Letters, 53 (2012) 1728-1731.

[42] A. Hasaninejed, M.R. Kazerooni, A. Zare, Catalysis Today, 196 (2012) 148-155.

[43] X. Wang, W.-W. Ma, L.-Q. Wu, F.-L. Yan, Journal of the Chinese Chemical Society, 57 (2010) 1341-1345.

[44] G. Ferey, C. Mellot-Draznieks, C. Serre, F. Millange, J. Dutour, S. Surble, I. Margiolaki,

Science, 309 (2005) 2040-2042.

[45] L. Bromberg, Y. Diao, H. Wu, S.A. Speakman, T.A. Hatton, Chemistry of Materials, 24 (2012) 1664-1675.

[46] H. Liu, Y. Li, H. Jiang, C. Vargas, R. Luque, Chemical Communications, 48 (2012) 8431-8433.

[47] M. Saikia, D. Bhuyan, L. Saikia, New Journal of Chemistry, 39 (2015) 64-67.

[48] A.D. Newman, D.R. Brown, P. Siril, A.F. Lee, K. Wilson, Physical Chemistry Chemical Physics, 8 (2006) 2893-2902.

[49] L. Frattini, M.A. Isaacs, C.M.A. Parlett, K. Wilson, G. Kyriakou, A.F. Lee, Applied Catalysis B: Environmental, 200 (2017) 10-18.

[50] N.V. Maksimchuk, O.V. Zalomaeva, I.Y. Skobelev, K.A. Kovalenko, V.P. Fedin, O.A.

Kholdeeva, Proceedings of the Royal Society A: Mathematical, Physical and Engineering Science, 468 (2012) 2017-2034.

[51] B.R. Knappett, P. Abdulkin, E. Ringe, D.A. Jefferson, S. Lozano-Perez, T.C. Rojas, A.

Fernandez, A.E.H. Wheatley, Nanoscale, 5 (2013) 5765-5772.

[52] G.M. Varga, E. Papaconstantinou, M.T. Pope, Inorganic Chemistry, 9 (1970) 662-667.

[53] X. Qian, X. Tong, Q. Wu, Z. He, F. Cao, W. Yan, Dalton Transactions, 41 (2012) 9897-9900.

[54] S.H. Jhung, J.H. Lee, J.W. Yoon, C. Serre, G. Férey, J.S. Chang, Advanced Materials, 19 (2007) 121-124.

[55] Q. Liu, L. Ning, S. Zheng, M. Tao, Y. Shi, Y. He, Sci Rep, 3 (2013) 2916.

[56] S. Bhattacharjee, C. Chen, W.-S. Ahn, RSC Adv., 4 (2014) 52500-52525.

[57] Y.K. Hwang, D.Y. Hong, J.S. Chang, S.H. Jhung, Y.K. Seo, J. Kim, A. Vimont, M. Daturi, C.

Serre, G. Ferey, Angewandte Chemie, 47 (2008) 4144-4148.

[58] J. Davarpanah, A.R. Kiasat, S. Noorizadeh, M. Ghahremani, Journal of Molecular Catalysis A: Chemical, 376 (2013) 78-89.

[59] Y.-F. Huang, M. Liu, Y.-Q. Wang, Y. Li, J.-M. Zhang, S.-H. Huo, RSC Adv., 6 (2016) 1536215369.

[60] X. Li, H. Xue, H. Pang, Nanoscale, 9 (2017) 216-222.

[61] E. Caliman, J.A. Dias, S.C.L. Dias, A.G.S. Prado, Catalysis Today, 107 (2005) 816-825.

[62] N.I.o.S.a. Technology, in, Gaithersburg, 2012.

[63] D. Julião, A.C. Gomes, M. Pillinger, L. Cunha-Silva, B. de Castro, I.S. Gonçalves, S.S. Balula, Fuel Processing Technology, 131 (2015) 78-86.

[64] Y. Xu, M. Lv, H. Yang, Q. Chen, X. Liu, W. Fengyu, RSC Advances, 5 (2015) 43473-43479.

[65] R. Tayebee, M.M. Amini, S. Pouyamanesh, A. Aliakbari, Dalton Trans, 44 (2015) 5888-5897.

[66] J.M. Khurana, D. Magoo, Tetrahedron Letters, 50 (2009) 7300-7303.

[67] K. Mazaahir, C. Ritika, J. Anwar, Chinese Science Bulletin, 57 (2012) 2273-2279. 
[68] M. Sayyafi, M. Seyyedhamzeh, H.R. Khavasi, A. Bazgir, Tetrahedron, 64 (2008) 2375-2378. [69] F. Yang, H.J. Zang, Q.K. Wang, B.W. Cheng, Y.L. Ren, X.L. Xu, in: Advanced Materials Research, Trans Tech Publ, 2011, pp. 1884-1887.

[70] H.R. Shaterian, M. Ghashang, M. Feyzi, Applied Catalysis A: General, 345 (2008) 128-133. [71] A.R. Kiasat, J. Davarpanah, Journal of Molecular Catalysis A: Chemical, 373 (2013) 46-54. [72] N. Janssens, L.H. Wee, S. Bajpe, E. Breynaert, C.E.A. Kirschhock, J.A. Martens, Chemical Science, 3 (2012) 1847-1850.

[73] H.R. Shaterian, F. Rigi, Starch - Stärke, 63 (2011) 340-346. 